\title{
Serial evaluation of retinal vascular changes in infants treated with intravitreal bevacizumab for aggressive posterior retinopathy of prematurity in zone I
}

${ }^{1}$ Miriam Hyman Children Eye Care Center, LV Prasad Eye Institute,

Bhubaneswar, India

${ }^{2}$ Kanuri Santhamma Center for Vitreo Retinal Disease, LV Prasad Eye Institute, Banjara Hills, Hyderabad, India

${ }^{3}$ Infosys Pediatric Center, Capital Hospital, Bhubaneswar, India

Correspondence: TR Padhi, Retina-Vitreous Service, LV Prasad Eye Institute, Patia, Bhubaneswar 751024, India Tel: +91 6743987 999; Fax: +916743987130 E-mail: drtapasranjan@ yahoo.co.in

Received: 5 June 2015 Accepted in revised form: 6 October 2015

Published online: 20 November 2015

\begin{abstract}
Purpose To evaluate the serial changes in retinal vasculature in infants treated with intravitreal bevacizumab (IVB) for aggressive posterior retinopathy of prematurity (APROP) in zone $\mathbf{I}$.

Methods Retrospective analysis of serial changes in retinal vasculature after IVB in the seven eyes of four babies with APROP in zone I.

Results The initial regression, following IVB, was dramatic with reduction in vessel caliber and marked thinning and invisibility of the bridging shunts. Resurgent vascular development was very slow radially though there was continued abnormal vascular growth circumferentially. Common findings in all eyes were tangled vasculature and fine saw-toothed shunts. The variable findings were (1) new closely packed multilayered bridging shunts, long arching mature looking vessels, and finally a ridge at the periphery ( $n=3$ eyes) at 52 weeks of postmenstrual age (PMA); (2) status quo at the stage of saw-toothed shunt and ridge in both eyes for a long time ( $n=2$ eyes); and (3) multiple retinal hemorrhages within the vascularized retina and thick preretinal hemorrhage overlying the saw-toothed shunts and ridge that persisted for another 3 weeks and regressed 2 weeks after laser $(n=1)$. The eyes that received bevacizumab alone (3) did not show any abnormal vascularization at 56 weeks of PMA or beyond.

Conclusions The retinal vascularization following IVB was different than normal in
\end{abstract}

TR Padhi ${ }^{1}$, T Das ${ }^{2}$, S Rath ${ }^{1}$, L Pradhan ${ }^{3}$, S Sutar ${ }^{1}$, KG Panda ${ }^{1}$, R Modi $^{1}$ and S Jalali ${ }^{2}$ terms of its time, speed, and morphology; few of these changes are first to be reported in the literature (Medline search) and warrants further studies.

Eye (2016) 30, 392-399; doi:10.1038/eye.2015.240; published online 20 November 2015

\section{Introduction}

With increase in premature birth in many parts of the world, retinopathy of prematurity (ROP) has become a leading cause of childhood blindness ${ }^{1}$ where vascular endothelial growth factors (VEGFs) have a key role in the pathogenesis. ${ }^{2,3}$ Recent years have witnessed the emergence of a more virulent form of ROP, the aggressive posterior ROP (APROP); this is commonly seen in the tiniest babies and affects zone I and posterior zone II. ${ }^{4}$ Early laser (current gold standard $)^{5}$ treatment as suggested in the Early Treatment for Retinopathy of Prematurity (ETROP) study ${ }^{6}$ does not rule out poor outcomes in this variant of ROP. ${ }^{7-9}$ Besides, laser therapy causes permanent damage to the peripheral retina, ${ }^{10}$ with increasing risk of visual field loss 9 and high refractive error in many with zone 1 disease. ${ }^{11}$ Hence, a quest continues to explore better and safer alternatives.

Bevacizumab is a recombinant humanized VEGF antibody that prevents VEGF from binding to its receptors. ${ }^{12}$ It blocks VEGFinduced angiogenesis and is approved by the US Food and Drug administration for intravenous use for metastatic colorectal cancer. Off-label bevacizumab currently used in wet age-related 
macular degeneration and in macular edema secondary to vascular retinopathies is increasingly considered for ROP. Bevacizumab (Avastin; Genentech, San Francisco, CA, USA) causes dramatic but temporary reduction in the disease course and has been claimed to avoid many side effects associated with laser. ${ }^{9}$ The initial enthusiasm of using bevacizumab monotherapy in zone 1 ROP has been tempered by the probability of its impact on normal ocular angiogenesis, late recurrences as well as its possible effects on many developing organs such as the brain, the kidneys and the lungs owing to the drug reaching the systemic circulation. ${ }^{2,13-15}$ In fact, some reports have questioned the use of this medication without clinical trials that mandates meticulous evaluation of multiple variables that normally precedes the introduction of drugs in clinical use. ${ }^{16}$

Thus a careful intensive documentation of sequential vascular changes following intravitreal bevacizumab (IVB) is necessary for judicious use in management of ROP. We studied the pattern of vascular changes and temporal sequence of retinopathy following IVB in seven eyes of four babies with ROP in zone I. Additionally, there was an opportunity to document and compare the effect of IVB (one eye) and laser (fellow eye) in one baby.

\section{Materials and methods}

This retrospective observational study was approved by the institutional review board and adhered to the tenets of the declaration of Helsinki. During our routine screening for ROP as per the National Neonatology Forum, India recommendations ${ }^{17}$ four babies (seven eyes) with APROP received IVB for compelling situations (Table 1) and were followed up carefully to intervene in case of worsening. All the examinations, photography, and treatments were carried out with written informed parental consent. IVB was injected at a concentration of $0.5 \mathrm{mg} / 0.02 \mathrm{ml}$ ( $40 \%$ of the normal adult dose) using a $30-\mathrm{G}$ needle $1 \mathrm{~mm}$ from the limbus after appropriate preparation of the injection site. ${ }^{18}$ Follow-up examinations with indirect ophthalmoscopy were carried out on days 1 and 7 and at 1-2 weeks interval thereafter till complete regression of retinopathy clinically by a single pediatric retina specialist (TRP). The babies were further examined at 3-6 months interval after clinical regression and continued at least up to 1.5 years to look for disease recurrences, if any. The findings were drawn in the patient records and documented as per ICROP-revisited standards. The eyes were serially imaged with RetCam (Clarity Medical Systems Inc., CA, USA) to document the vascular changes (development/regression/reactivation). A trained photographer (KGP) montaged the images wherever possible. The pediatric retina specialist (TRP) drew the free-hand cartoons; he also analyzed the RetCam images and the fundus drawing retrospectively at a later date.

\section{Results}

\section{Observations}

Table 1 shows the gestational age, birth weight, postmenstrual age (PMA) at examination, significant perinatal events, and, finally, type and indication of treatment. While two babies were managed only with

Table 1 Case profile and indications for intravitreal bevacizumab

\begin{tabular}{|c|c|c|c|c|}
\hline Case eye & Significant perinatal history & Diagnosis & Management & Indication for IVB \\
\hline \#1 OU & $\begin{array}{l}\text { GA: } 26 \text { weeks; BW: } 1110 \mathrm{~g} \text {. } \\
\text { Severe respiratory distress. } \\
\mathrm{O}_{2} \text { supplement }{ }^{\mathrm{n}} \times 6 \text { weeks }\end{array}$ & APROP & $\begin{array}{l}\text { IVB at } 30 \text { weeks. PMA. Vascularization } \\
\text { remained quiet till PMA } 38 \text { weeks, } \\
\text { when laser was carried out in OU }\end{array}$ & Continued unstable vitals \\
\hline \#2 OS & $\begin{array}{l}\text { GA } 28 \text { weeks; BW } 920 \text { g. } \\
\text { H/o twin pregnancy (other } \\
\text { sibling expired after birth). } \\
\text { Respiratory distress. } \\
\mathrm{O}_{2} \text { supplement }{ }^{\mathrm{n}} \times 5 \text { weeks. } \\
\text { Thrombocytopenia and anemia. } \\
\text { Blood transfusion twice }\end{array}$ & APROP & $\begin{array}{l}\text { Laser OD. } \\
\text { IVB OS at } 32 \text { weeks of PMA }\end{array}$ & $\begin{array}{l}\text { Persistent bradycardia } \\
\text { and apnea after laser under } \\
\text { TA in OD. So OS received } \\
\text { IVB }\end{array}$ \\
\hline \#3 OU & $\begin{array}{l}\text { GA: } 31 \text { weeks, BW: } 1195 \mathrm{~g} . \\
\text { Respiratory distress, septicemia, } \\
\mathrm{O}_{2} \text { supplement }{ }^{\mathrm{n}} \times 4 \text { weeks }\end{array}$ & APROP & IVB OU at 34 weeks of PMA & $\begin{array}{l}\text { Very sick. } \\
\text { Unstable vitals }\end{array}$ \\
\hline \#4 OU & $\begin{array}{l}\text { GA: } 28 \text { weeks, BW: } 1000 \mathrm{~g} \text {. } \\
\text { Respiratory distress and } \\
\text { apnea, HIE } \\
\mathrm{O}_{2} \text { supplement }{ }^{\mathrm{n}} \times 5 \text { weeks. } \\
\text { Recovered very well thereafter }\end{array}$ & $\begin{array}{l}\text { APROP } \\
\text { (NVI, non-dilating pupil). } \\
\text { Vitreous haze, shunt and } \\
\text { tortuosity (baby too sick to } \\
\text { image with RetCam) }\end{array}$ & IVB OU at 32 weeks of PMA & $\begin{array}{l}\text { Very sick. } \\
\text { Unstable vitals (even fundus } \\
\text { examination was also } \\
\text { difficult) }\end{array}$ \\
\hline
\end{tabular}

Abbreviations: APROP, aggressive posterior retinopathy of prematurity; BW, birth weight; GA, gestational age; HIE, hypoxic ischemic encephalopathy; IVB, intravitreal bevacizumab; NVI, neovascularization of the iris; PMA, postmenstrual age; Supplement ${ }^{\mathrm{n}}$, supplementation; TA, topical anesthesia. 
Table 2 Sequential changes in retinal vasculature of cases 1-4 (7 eyes) under intravitreal bevacizumab and final outcome

\begin{tabular}{ll}
\hline Fundus photo and cartoon & Characteristics \\
\hline Stage of rapid quietening & $\begin{array}{l}\text { Reduction in vessel caliber, } \\
\text { dilatation and tortuosity of retinal } \\
\text { vessels, shunts indistinct }\end{array}$ \\
\end{tabular}

Stage of slow and abnormal vascular changes
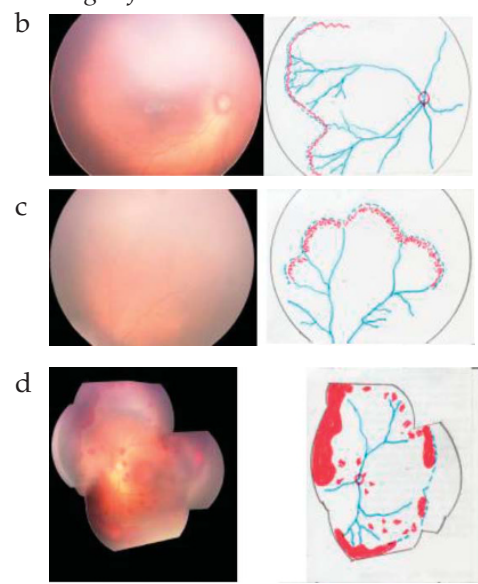

e

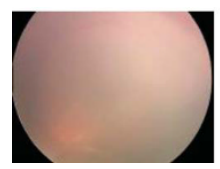

$\mathrm{f}$

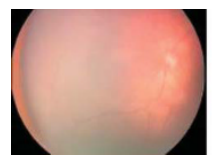

Stage of regression

g

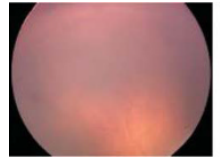

h
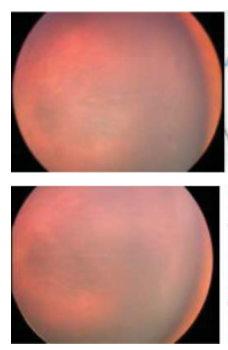

j

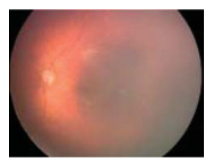

Saw-toothed shunt

Tangled vasculature

Extensive retinal heme and preretinal heme

Closely packed bridging vessels, multiple rows

$\mathrm{ACV}$ with radial branching

Ridge formation

Ridge doubling

Ridge regression ACV less apparent

No clinically recognizable vascular abnormality
\#1 OD \#1 OS \#2 OS \#3 OD \#3 OS \#4 OS \#4 OD

促

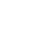

(1)


bevacizumab, the other two received additional laser treatment for compelling situations. One received laser 8 weeks after IVB because of follow-up compliance issue and the other 10 weeks after injection for sudden retinal and preretinal hemorrhages that increased with time. Table 2 shows the earliest retinal changes, serial changes in retinal vasculature following IVB, and final outcome in all four babies (seven eyes). The fundus images and the accompanying cartoons inserted within the table depict the major prototype retinal changes common to all the seven eyes. The exact timeline and sequence of changes after IVB in each eye are shown in Supplementary Figures S1-S8. We did not observe any significant systemic complications in any of these babies through last follow-up. Similarly, there were no recognizable vascular anomalies in the four eyes once they were lasered.

\section{Descriptive findings}

The common features noted in all the eyes were as follows. Following IVB, there was a rapid and marked quietening of the disease activity, including plus component (a false sign of complete disappearance of disease) within a week followed by a very slow phase of vascular development that continued up to 11 weeks. The radial growth of the retinal vasculature was remarkably slower than the circumferential growth that was rapid but abnormal. These included saw-toothed shunts (Table 2, row a), tangled vasculature (a confused bundle of hair brush-like super numerous fine vessels at vascular-avascular junction; Table 2, row b) and demarcation line in all the seven eyes (Table 2, rows a and b), persistence in this stage for a long period in five eyes, closely packed multiple rows of vessels arching between the ends of the major vessels in some quadrants (Table 2, row e), and finally mature single abnormal circumferential retinal vessels with radial branches (Table 2, row $\mathrm{f}$ ) at periphery in three eyes. There was formation of a ridge similar to classical ROP and non-dichotomous branching of retinal vessels toward the end of regression in five eyes (Table 2, row g). The sawtoothed shunts were fine and less arching than the shunts prior to injections. The abnormal circumferential vessels were the last to appear before regression. They appeared morphologically similar and were a continuation of the major vascular arcades. With increase in PMA, they appeared progressively wider, steeper, and peripheral.

In one case (case \#4), the retinopathy was stagnant at the stage of saw-toothed shunt and started forming a ridge in some other quadrant in both eyes. This baby behaved differently. The left eye developed retinal hemorrhages all over the vascularized retina and preretinal hemorrhages overlying the shunt and the ridge (Table 2, row $\mathrm{d}$ ). The baby was not on systemic anticoagulant of any sort. The hematological investigations, including platelet count and prothrombin time, were normal except a low hemoglobin concentration of $6.1 \mathrm{~g} \%$. The fact that the hemorrhages were concentrated more at the site of shunt and ridge suggested the contribution of immature retinal vasculature to bleeding. After two units of blood transfusion within a week, the preretinal hemorrhages increased both in extent and severity and persisted till laser was carried out 3 weeks later. The right eye showed early retinal hemorrhages over the ridge and hence it was also lasered.

We observed that the duration of total regression of retinopathy differed with the type of treatment. It was 21-31 weeks with IVB monotherapy (3 eyes), 9-11 weeks in eyes rescued with laser after IVB (4 eyes), and 3 weeks with laser monotherapy (right eye of baby \#2).

\section{Discussion}

The fact that there were many similarities in the pattern of retinal vascularization in these eyes indicated that the observed changes were not just a chance association or the result of some systemic factors. In fact, with all other collateral health problems remaining similar, the retinopathy in the lasered (right) eye of the baby \#2 regressed in an expected pattern in 3 weeks compared with the bevacizumab-treated (left) eye where the vascular abnormality persisted even up to 52 weeks of PMA. Similarly, in babies \#1 and \#4, the initial vascular abnormality under bevacizumab did not persist, and other vascular abnormality did not appear after both the eyes were lasered. Of course, longer period (may be, years) of follow-up would be needed to look and compare the long-term changes in ocular biometry, refractive error, and visual field changes in both the groups. Contrary to the earlier reports ${ }^{19-24}$ that showed that IVB does not affect the normal retinal vascularization except a slowing down of the speed of normalization, we observed that bevacizumab significantly alters the natural course of APROP in zone I-the severity, the regression time sequence, and the pattern of retinal vascularization process. These changes in retinal vasculature were also different from the pattern of APROP regression either naturally or following laser. We compared the observed vascular events with reports on similar changes of any kind after IVB ${ }^{15,25-29}$ (Table 3) at different doses reported so far in the literature. The saw-toothed shunts observed in all the seven eyes in our series had a striking resemblance to the recent description of 'tungsten filament sign' by Yetik et $a^{29}$ and needs special mention. Although we agree with them that these could be pathognomonic sign of IVB injection in preterm babies, the fact that there were severe preretinal hemorrhage overlying it in one eye and progression to abnormal 
Table 3 Post-intravitreal bevacizumab retinal vascular anomaly past reports vis-à-vis observations in the present series

\begin{tabular}{|c|c|c|c|c|}
\hline $\begin{array}{l}\text { Author, } \\
\text { year, } \\
\text { country }\end{array}$ & ROP status at intervention & IVB (dose: $m g$ ) & Mode of observation & Observed vascular anomaly \\
\hline $\begin{array}{l}\text { Wu et al. }{ }^{15} \\
\text { 2011, } \\
\text { Taiwan }\end{array}$ & Stages $3,4 \mathrm{~A}$ and 5 & 0.625 & $\mathrm{I} / \mathrm{O}$ & Preretinal hemorrhage \\
\hline $\begin{array}{l}\text { Hu et al. }{ }^{27} \\
2012, \\
\text { USA }\end{array}$ & Prethreshold (type 1) & $0.625-0.750$ & $\mathrm{I} / \mathrm{O}$ & Anomalous circumferential vessel \\
\hline $\begin{array}{l}\text { Henaine-Berra } \\
\text { et al. }{ }^{28} \\
2014, \\
\text { Mexico }\end{array}$ & $\begin{array}{l}\text { Threshold } \\
\text { Prethreshold }\end{array}$ & 0.750 & $\mathrm{I} / \mathrm{O}$ & $\begin{array}{l}\text { 1. Vascular loops } \\
\text { 2. Peripheral retinal avascularity }\end{array}$ \\
\hline $\begin{array}{l}\text { Tahija et al. }{ }^{29} \\
2014, \\
\text { Indonesia }\end{array}$ & $\begin{array}{l}\text { APROP } \\
\text { Posterior zone II and plus }\end{array}$ & $\begin{array}{l}\text { Not available in the } \\
\text { article }\end{array}$ & $\begin{array}{l}\text { I/O } \\
\text { FFA with RetCam }\end{array}$ & $\begin{array}{l}\text { 1. Circumferential vessel } \\
\text { 2. Peripheral retinal avascularity }\end{array}$ \\
\hline $\begin{array}{l}\text { Lepore et } a l .{ }^{30} \\
2014, \\
\text { Rome }\end{array}$ & Type1 zone I & 0.50 & $\begin{array}{l}\text { I/O } \\
\text { FFA with RetCam }\end{array}$ & $\begin{array}{l}\text { 1. Avascular retina } \\
\text { 2. Absence of FAZ } \\
\text { 3. Tangled vasculature } \\
\text { 4. Abnormal arteriovenous shunts }\end{array}$ \\
\hline $\begin{array}{l}\text { Yetik et al. }{ }^{31} \\
2014 \\
\text { Turkey }\end{array}$ & $\begin{array}{l}\text { Prethreshold (type 1) } \\
\text { Threshold } \\
\text { APROP }\end{array}$ & $\begin{array}{l}0.625 \text { (multiple inj.in } \\
\text { some) }\end{array}$ & $\mathrm{I} / \mathrm{O}$ & $\begin{array}{l}\text { Tungsten filament sign } \\
\text { Similar to saw- toothed shunt in } \\
\text { the present series } \\
\text { Sign of regression }\end{array}$ \\
\hline Present series & $\begin{array}{l}\text { APROP } \\
\text { Hybrid ROP (in zone I and } \\
\text { zone II posterior) }\end{array}$ & 0.50 & $\begin{array}{l}\text { I/O } \\
\text { Fundus photos with } \\
\text { RetCam }\end{array}$ & $\begin{array}{l}\text { 1. Saw-toothed shunt } \\
\text { 2. Tangled vasculature } \\
\text { 3. Closely packed multiple bridging } \\
\text { shunts } \\
\text { 4. Anomalous circumferential } \\
\text { vessels } \\
\text { 5. Retinal and preretinal } \\
\text { hemorrhage } \\
\text { 6. Ridge formation }\end{array}$ \\
\hline
\end{tabular}

Abbreviations: APROP, aggressive retinopathy of prematurity; FFA, fundus fluorescein angiogram; FAZ, foveal avascular zone; I/O, indirect ophthalmoscopy; IVB, intravitreal bevacizumab.

circumferential vessels in the other 3 eyes makes us to believe that they may not always be the marker of regression and should be followed up with care and caution. The initial apparent disappearance could just represent thinning and invisibility of those shunts under bevacizumab that reappear as abnormal circumferential vessel as the effect of the drug wanes off.

The vascular change pattern could be grouped into the following three phases (Figure 1): the phase of rapid quietening of disease (within a week); the phase of slow vascular development (up to 11 weeks in the absence of any intervention); and finally the phase of regression (up to 16 weeks) that sets in with a ridge similar to classical stage 2 of ROP.

The stage of rapid quietening occurs due to a rapid neutralization of the existing vitreous VEGF immediately following the anti-VEGF injection. The pathogenesis of the abnormal vascular events in the second phase is most intriguing. These changes happen at a stage when the intravitreal concentration of bevacizumab is declining and new VEGFs secreted by residual avascular retina and other natural antiangiogenic growth factors such as transforming growth factor- $\beta$ (TGF- $\beta)^{30}$ are on the rise. Probably a mismatch between these pro-angiogenic and antiangiogenic factors with respect to both time and relative proportion accounts for these abnormal vascular changes. The abnormal circumferential vessels that grow towards the end of the second phase appeared apparently more mature, wider than their saw-toothed counterpart at the beginning and could represent a partial compensation for temporary cessation in radial progression. We believe some of the radial branches from the circumferential vessel could be a manifestation of the same. In the final phase of regression, a ridge-like classical ROP appears and could be due to elimination of already secreted VEGFs from vitreous, decline in the production of natural VEGFs, further accumulation of TGF- $\beta$ with increase in PMA, and improvement in systemic status. Interestingly, the tangled vasculature and abnormal circumferential vessel in this phase had striking similarity to the vascular changes described by Kashani et $a l^{30}$ in familial exudative 


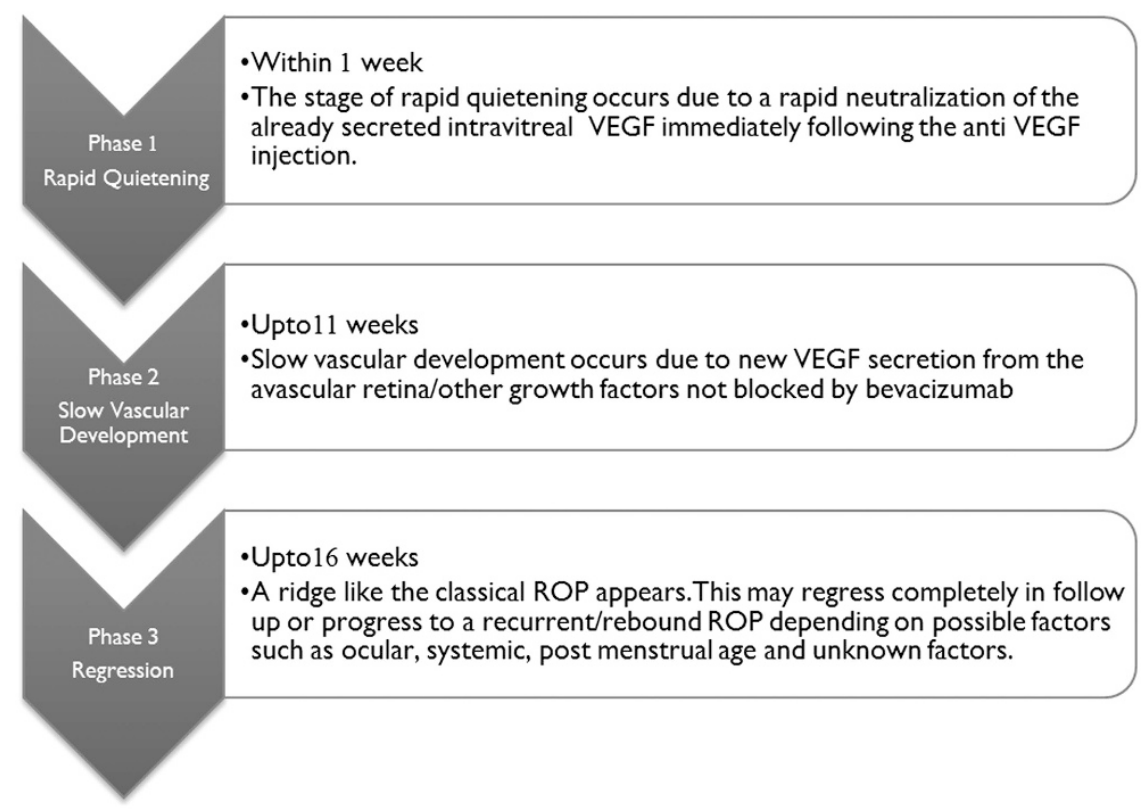

Figure 1 Pathogenesis of the three major phases of vascular changes in the seven eyes under IVB.

retinopathy (an ROP mimicker). One wonders at the reason for this common path.

Bevacizumab does not have any effect on the secretion of new VEGFs; this is secreted unabated from the avascular tissues till the eye receives laser or the retina matures. Although the VEGF secretion depends primarily on the amount of avascular retina, other factors such as PMA and the 'sickness' of baby at that time, including respiratory distress, sepsis, poor weight gain, and so on, also contribute variably. These factors in turn decide the retinopathy pattern (regression, progression, or recurrence) and severity while escaping from the influence of reducing bevacizumab levels in the eye.

Small sample size (too small to detect statistically significant difference in systemic side effects), absence of angiographic demonstration of vascular anomalies, poor image quality to document the fine vascular changes at the periphery, and difficulty in imaging the extreme retinal periphery of babies once they grew up were few limitations of the study. We relied on indirect ophthalmoscopy primarily, supplemented with RetCam images. Despite the fact that we could not obtain good peripheral retinal images with RetCam in babies beyond 52 weeks, we did not want to hazard babies with repeated general anesthesia in our existing set-up for imaging alone.

The strength of this study is the frequent follow-up and documentation of retinal vascular changes as close as every week rather than over a fortnight or a month till complete clinical resolution (Supplementary Figures S1-S8). As a result, we had a unique opportunity to study and document the vascular changes every week rather than over a fortnight or a month. We observed many changes that add to our understanding of some of the vascular events that occur following bevacizumab and possibly other anti-VEGF agents. The three eyes treated with bevacizumab monotherapy finally approached same morphological end points without any clinically evident structural changes (such as laser scars) at 56-62 weeks of PMA. This has to be weighed against the frequent, long, and skilled follow-up, possible noncompliance, difficulty of scleral indentation without anesthesia in a grown up baby, absence of guidelines on definite end point of screening in bevacizumab monotherapy, and the subclinical functional and angiographic changes that might be happening. The ophthalmologist's role becomes crucial in not only ensuring close follow-up of babies treated with bevacizumab monotherapy for a very long period but also add laser if compliance to follow-up becomes an issue in the event of persistent avascular retina even in the absence of re-activation.

Although observations by others will be welcome additions, we feel that the ocular changes observed here could also provide insights into possible vascular changes happening in other immature or incompletely vascularized tissues such as the choroid or other organs of the body such as lungs and kidneys, under the influence of the systemically released bevacizumab. Effect of IVB on choroid and choroidal circulation is an emerging concept. In fact, earlier reports ${ }^{32-34}$ on choroidal thinning and rupture after IVB could indicate the same. Enhanced depth choroidal imaging with spectral domain optical coherence tomography and neonatal indocyanin green 
angiography could explore abnormalities in choroidal vasculature under IVB. Serum VEGF level is reportedly suppressed for 2 months after IVB $(0.625 \mathrm{mg})$ in patients with type 1 ROP (as defined by the early treatment for ROP guidelines). ${ }^{35}$ In the fetus, VEGF is expressed in most tissues and has a vital role in organogenesis and neurodevelopment. ${ }^{36}$ This raises the concern that important normal physiological effects associated with VEGFs might get inhibited leading to abnormal organogenesis. Very preterm infants at risk for severe ROP have subnormal functioning of many organ systems for the rest of their lives. Anti-VEGF treatment may have the capacity to reduce their reserves even further. ${ }^{35}$ Unfortunately, we do not have access to see the growing vasculature of the various developing organs as clearly and directly as retinal blood vessels in an infant.

The retinal vasculature has many similarities with the CNS and renal blood vessels. So the possibility of vascular abnormalities in these organs similar to that observed in the present series cannot be ruled out. These effects might not be clinically obvious until decades after treatment. Reports show that bevacizumab even at a dose of 0.25 and $0.375 \mathrm{mg}$ show their efficacy in ROP. ${ }^{37,38}$ It would be useful to explore the efficacy vis-à-vis vascular safety of IVB with ultralow doses than the current practice by intensive meticulous observation and follow-up. We hope future research will clear the path for a newer and better anti-VEGF agent or will explore an ultralow dose IVB therapy that would show high efficacy without any adverse effect on the normal retinal vascularization.

\section{Summary}

\section{What was known before}

- Aggressive retinopathy of prematurity (APROP) in zone I continues to posses management challenges. Bevacizumab is increasingly considered for APROP in zone I. Safety concerns of intravitreal bevacizumab (IVB) on retinal vasculature in prematurely born infants continues.

What this study adds

- Bevacizumab alters the pace and pattern of the developing retinal vasculature.

- Radial vascular growth is slower than the abnormal circumferential development.

- Vascular abnormalities: saw-toothed shunts, tangles, multiple arcades, large loops.

- Retinal vascular abnormalities could mirror the same in the developing brain and kidney.

- Need to evaluate safety and efficacy of IVB in retinopathy of prematurity at an ultralow dose.

\section{Conflict of interest}

The authors declare no conflict of interest.

\section{Acknowledgements}

This work was supported by Hyderabad Eye Research Foundation.

\section{References}

1 Mintz-Hittner HA. Treatment of retinopathy of prematurity with vascular endothelial growth factor inhibitors. Early Hum Dev 2012; 88(12): 937-941.

2 Hartnett ME. Pathophysiology and mechanism of severe retinopathy of prematurity. Ophthalmology 2015; 122(1): 200-210.

3 Hartnett ME. Vascular endothelial growth factor antagonist therapy for retinopathy of prematurity. Clin Perinatol 2014; 41(4): 925-943.

4 An International Committee for the Classification of Retinopathy of Prematurity. The International Classification of Retinopathy of Prematurity Revisited. Arch Ophthalmol 2005; 123: 991-999.

5 Mutlu FM, Sarici FU. Treatment of retinopathy of prematurity: a review of conventional and promising new therapeutic options. Int J Ophthalmol 2013; 6: 228-236.

6 Early Treatment for Retinopathy of Prematurity Cooperative Group. Revised indications for the treatment of retinopathy of prematurity: results of the Early Treatment for Retinopathy of Prematurity randomized trial. Arch Ophthalmol 2003; 121(12): 1684-1694.

7 Azuma N, Ishikawa K, Hama Y, Hiraoka M, Suzuki Y, Nishina S. Early vitreous surgery for aggressive posterior retinopathy of prematurity. Am J Ophthalmol 2006; 142(4): 636-643.

8 Vinekar A, Trese MT, Capone Jr A. Evolution of retinal detachment in posterior retinopathy of prematurity: impact on treatment approach. Am J Ophthalmol 2008; 145(3): 548-555.

9 Good WV, Hardy RJ, Dobson V, Palmer EA, Phelps DL, Tung $\mathrm{B}$ et al. Final visual acuity results in the early treatment for retinopathy of prematurity study. Arch Ophthalmol 2010; 128 (6): 663-671.

10 Mintz-Hittner HA, Kennedy KA, Chuang AZ, BEAT-ROP Cooperative Group. Efficacy of intravitreal bevacizumab for stage 3+ retinopathy of prematurity. N Engl J Med 2011; 364 (7): 603-615.

11 Shah PK, Ramakrishnan M, Sadat B, Bachu S, Narendran V, Kalpana N. Long term refractive and structural outcome following laser treatment for zone 1 aggressive posterior retinopathy of prematurity. Oman J Ophthalmol 2014; 7(3): 116-119.

12 Lin YS, Nguyen C, Mendoza JL, Escandon E, Fei D, Meng YG et al. Preclinical pharmacokinetics, interspecies scaling, and tissue distribution of a humanized monoclonal antibody against vascular endothelial growth factor. J Pharmacol Exp Ther 1999; 288(1): 371-378.

13 Darlow BA, Ells AL, Gilbert C.E, Gole GA, Quinn GE. Are we there yet? Bevacizumab therapy for retinopathy of prematurity. Arch Dis Child Fetal Neonatal Ed 2013; 98(2): F170-F174.

14 Sato T, Wada K, Arahori H, Kuno N, Imoto K, Iwahashi-Shima C et al. Serum concentrations of bevacizumab (Avastin) and vascular endothelial growth factor in infants with retinopathy of prematurity. Am J Ophthalmol 2012; 153(2): 327-333.e1. 
15 Wu WC, Yeh PT, Chen SN, Yang CM, Lai CC, Kuo HK. Effects and complications of bevacizumab use in patients with retinopathy of prematurity: a multicenter study in Taiwan. Ophthalmology 2011; 118(1): 176-183.

16 Micieli JA, Micieli A, Smith AF. Identifying systemic safety signals following intravitreal bevacizumab: systematic review of the literature and the Canadian Adverse Drug Reaction Database. Can J Ophthalmol 2010; 45: 231-238.

17 Pejaver RK, Vinekar A, Bilagi A. National Neonatology Forum, Evidence Based Clinical Practice Guidelines, Chapter on Retinopathy of Prematurity, NNF India, Guidelines 2010, pp 253-262. Available at: http:// aimaonline.org/iap-neochap-2013/uploads/acd-corner/ nnf_guidelines-2011.pdf (accessed 11 November 2015).

18 Aiello LP, Brucker AJ, Chang S, Cunningham Jr ET, D'Amico DJ, Flynn Jr HW et al. Evolving guidelines for intravitreous injections. Retina 2004; 24(5 Suppl): s3-s19.

19 Quiroz-Mercado H, Martinez-Castellanos MA, Hermamdez-Rojas ML, Salazar-TeranN, Chan RV. Antiangiogenic therapy with intravitreal bevacizumab for retinopathy of prematurity. Retina 2008; 28(3 Suppl): S19-S25.

20 Mintz-Hittner HA, Kuffel Jr RR . Intravitreal injection of bevacizumab (avastin) for treatment of stage 3 retinopathy of prematurity in zone I or posterior zone II. Retina 2008; 28: 831-838.

21 Şahin A, Şahin M, Cingü AK, Çınar Y, Türkcü FM, Yüksel H et al. Intravitreal bevacizumab monotherapy for retinopathy of prematurity. Pediatr Int 2013; 55(5): 599-603.

22 Dani C, Frosini S, Fortunato P, Bertini G, Pratesi S, Pollazzi L et al. Intravitreal bevacizumab for retinopathy of prematurity as first line or rescue therapy with focal laser treatment. A case series. J Matern Fetal Neonatal Med 2012; 25(11): 2194-2197.

23 Reynolds JD. Bevacizumab for retinopathy of prematurity. $N$ Engl J Med 2011; 364(7): 677-678.

24 Kong L, Mintz-Hittner HA, Penland RL, Kretzer FL, ChevezBarrios P. Intravitreous bevacizumab as anti-vascular endothelial growth factor therapy for retinopathy of prematurity: a morphologic study. Arch Ophthalmol 2008; 126 (8): 1161-1163.

25 Hu J, Blair MP, Shapiro MJ, Lichtenstein SJ, Galasso JM, Kapur R. Reactivation of retinopathy of prematurity after bevacizumab injection. Arch Ophthalmol 2012; 130(8): 1000-1006.

26 Henaine-Berra A, Garcia-Aguirre G, Quiroz-Mercado H, Martinez-Castellanos MA. Retinal fluorescein angiographic changes following intravitreal anti-VEGF therapy. J AAPOS 2014; 18(2): 120-123.

27 Tahija SG, Hersetyati R, Lam GC, Kusaka S, McMenamin PG. Fluorescein angiographic observations of peripheral retinal vessel growth in infants after intravitreal injection of bevacizumab as sole therapy for zone I and posterior zone II retinopathy of prematurity. Br J Ophthalmol 2014; 98(4): 507-512.

28 Lepore D, Quinn GE, Molle F, Baldascino A, Orazi L, Sammartino $\mathrm{M}$ et al. Intravitreal bevacizumab versus laser treatment in type 1 retinopathy of prematurity: report on fluorescein angiographic findings. Ophthalmology 2014; 121 (11): 2212-2219.

29 Yetik H, Gunay M, Sirop S, Salihoglu Z. Intravitreal bevacizumab monotherapy for type-1 prethreshold, threshold, and aggressive posterior retinopathy of prematurity-27 month follow-up results from Turkey. Graefes Arch Clin Exp Ophthalmol 2014; 253(10): 1677-1683.

30 Kashani AH, Brown KT, Chang E, Drenser KA, Capone A, Trese MT. Diversity of retinal vascular anomalies in patients with familial exudative vitreoretinopathy. Ophthalmology 2014; 121(11): 2220-2227.

31 Jalali S, Balakrishnan D, Zeynalova Z, Padhi TR, Rani PK. Serious adverse events and visual outcomes of rescue therapy using adjunct bevacizumab to laser and surgery for retinopathy of prematurity. The Indian Twin Cities Retinopathy of Prematurity Screening database Report number 5. Arch Dis Child Fetal Neonatal Ed 2013; 98: F327-F333.

32 Chhablani J, Rani PK, Balakrishnan D, Jalali S. Unusual adverse choroidal reaction to intravitreal bevacizumab in aggressive posterior retinopathy of prematurity: the Indian Twin Cities ROP screening (ITCROPS) data base report number 7. Semin Ophthalmol 2014; 29(4): 222-225.

33 Mutlu FM, Sarici SU. Treatment of retinopathy of prematurity: a review of conventional and promising new therapeutic options. Int J Ophthalmol 2013; 6(2): 228-236.

34 Atchaneeyasakul LO, Trinavarat A. Choroidal ruptures after adjuvant intravitreal injection of bevacizumab for aggressive posterior retinopathy of prematurity. J Perinatol 2010; 30(7): 497-499.

35 Wu WC, Lien R, Liao PJ, Wang NK, Chen YP, Chao AN et al. Serum levels of vascular endothelial growth factors and related factors after intravitreous bevacizumab injection for retinopathy of prematurity. JAMA Ophthalmol 2015; 133(4): 391-397.

36 Hard AL, Hellstrom A. On safety, pharmacokinetics and dosage of bevacizumab in ROP treatment: a review. Acta Paediatr 2011; 100(12): 1523-1527.

37 Kuniyoshi K, Sugioka K, Sakuramoto H, Kusaka S, Wada N, Shimomura Y. Intravitreal injection of bevacizumab for retinopathy of prematurity. Jpn J Ophthalmol 2014; 58(3): 237-243.

38 Harder BC, von Balz S, Jonas JB, Schlichtenbrede FC. Intravitreal low-dosage bevacizumab for retinopathy of prematurity. Acta Ophthalmol 2014; 92(6): 577-581. 